\title{
INTEGRACIÓN, ETNICIDAD Y ACCIÓN EDUCATIVA
}

\author{
IGNASI BRUNET, ANGEL BELZUNEGUI e INMA PASTOR
}

Universidad Rovira i Virgili. Tarragona

\author{
PALABRAS CLAVE ADICIONALES \\ Inmigración, Acción educativa, Etnicidad. \\ ADDITIONAL KEYWORDS \\ Immigration, Education Policy, Ethnicity.
}

\begin{abstract}
RESUMEN. En este artículo se presenta los resultados de una investigación realizada en los centros educativos de educación primaria e infantil de las comarcas del Camp de Tarragona. El objetivo del estudio fue conocer cómo se desarrollan las relaciones entre la población autóctona y la inmigrada extracomunitaria en el marco de la acción educativa, así como observar las acciones que ponen en marcha los maestros y los centros educativos en el tratamiento de los problemas que pueden generarse por el efecto de la inmigración. La investigación combinó técnicas cuantitativas (con la realización de 577 cuestionarios a maestros y maestras) y cualitativas (con la realización de 118 entrevistas en profundidad a los directores de todos los centros educativos que tuvieran inmigrantes de procedencia extracomunitaria y varios grupos de discusión en los que participaron padres y madres inmigrantes y autóctonos y maestros).
\end{abstract}

SUMMARY. In this article we present the results of a study carried out in primary and infant schools in the region of Tarragona. In this study we analysed the development of the relationship between the autochthonous and the non-EU immigrant populations within the framework of education action. We also observed the practices carried out by teachers and schools for tackling any problems due to the effects of immigration. The study combined quantitative techniques ( 577 questionnaires completed by primary and infant teachers) and qualitative techniques (118 in-depth interviews with the head teachers of all the schools with non-EU immigrant pupils and various discussion groups in which teachers and immigrant and autochthonous parents all took part).

\author{
E-mail: ibic@fcee.urv.es abe@fcee.urv.es ipig@fcj.urv.es
}

Revista Internacional de Sociología (RIS)

Tercera Época, $\mathrm{N}^{\circ}$ 36, Septiembre-Diciembre, 2003, pp. 115-133. 


\section{INTRODUCCIÓN}

Este artículo presenta, de forma resumida, algunos de los resultados de un estudio realizado el año 2002 por un grupo de profesores de la Universitat Rovira i Virgili, centrado en los procesos de incorporación al sistema educativo de los hijos de familias de origen inmigrante. Estudio que está en sintonía con la preocupación europea sobre los mecanismos de inserción social de los inmigrantes, mecanismos entre los que destaca el sistema educativo como uno de los más importantes por la acción que tiene sobre las futuras generaciones. La Unión Europea (UE), a través de la Iniciativa Equal (2000-2006), insiste en la necesidad de los estudios para el conocimiento de las situaciones de desigualdad y exclusión social de los llamados grupos de riesgo entre los que se encuentra la población inmigrante; asimismo, la propia Iniciativa Equal insiste en la necesidad de que, desde la sociedad čivil, se formulen planteamientos de propuestas de actuación para diferentes colectivos susceptibles de exclusión, marginación social, etc. El sistema educativo puede jugar un papel importante en la realización de este tipo de propuestas por la virtualidad que tiene de vincular diferentes agentes sociales.

Nos planteamos conocer cómo son las relaciones que se establecen entre la población autóctona y la inmigrada en el marco de la acción educativa. Nuestra hipótesis de partida se expresó de la siguiente forma genérica: los procesos de etnificación de la población inmigrada dificultan la integración social de los individuos. Como hipótesis derivada nos interesó destacar el hecho de que a medida de que se consolida la etnificación de la población inmigrada, es más probable que aparezcan conflictos entre las familias y la escuela, hecho que redunda en las dificultades de integración de los inmigrantes. De aquí que en el trabajo de investigación nos planteáramos estudiar el efecto que la etnificación de la población inmigrada tiene sobre la integración de los individuos. El análisis se ha concretado en el ámbito de las relaciones que se generan a partir de la incorporación, en el sistema educativo, de los hijos de familias inmigrantes que llegan a las comarcas del Camp de Tarragona'; de esta manera, nos ha interesado conocer las experiencias de participación del colectivo inmigrante en la inserción educativa de sus hijos.

Acotamos el alcance de nuestro análisis en uno de los colectivos de extranjeros, los de origen extracomunitario, ya que entre estos y los niños de origen comunitario hay diferencias tan grandes que haría imposible un tratamiento simultáneo y generalizado de sus respectivas inserciones educativas. Por otro lado, el colectivo de niños extracomunitarios es, tanto en cifras absolutas como

\footnotetext{
' El Camp de Tarragona es el territorio que comprende las 6 comarcas que rodean la ciudad de Tarragona y que engloba el $74,1 \%$ de la población de toda la provincia de Tarragona. Con fecha de 2001 las cifras de población censada en este territorio se sitúan en 453.289 personas, según el censo de la población.
} 
porcentuales, más numeroso que el colectivo de comunitarios en las comarcas del Camp de Tarragona.

A efectos de nuestro estudio entendimos por integración social de los inmigrantes la situación personal en la que se conjuga positivamente el despliegue de ciertos materiales sociales (acceso a vivienda, educación, trabajo, servicios sociales, servicios sanitarios, ocio...) sin que se presenten graves conflictos entre el individuo y los espacios que comparte con el resto de la población. A pesar de que puede existir un gradiente de integración en diversos ámbitos, podemos hablar de un proceso exitoso de integración social general cuando el inmigrante alcanza y tiene acceso a dichos materiales sociales, los combina con libertad y tiene, además, una percepción de bienestar personal en su proceso de integración. Definimos también el concepto de etnificación de los inmigrantes como un proceso que lleva al inmigrante a identificarse, a efectos de relaciones sociales, casi exclusivamente con una dimensión religiosa, idiomática, de procedencia, etc. Este concepto, tal y como lo manejamos en la investigación, supone diferentes grados de rechazo activo a formas culturales, sociales, políticas, religiosas, etc., ajenas a las propias normas que rigen la identificación. Entendemos que, mayoritariamente, el colectivo de inmigrantes está formado por los denominados inmigrantes económicos, es decir, aquellos que provienen de países no desarrollados o en vías de desarrollo con la voluntad de encontrar mejores condiciones de vida y de trabajo.

\section{DESCRIPCIÓN METODOLÓGICA DE LA INVESTIGACIÓN}

La investigación que da pie a este artículo se ha desarrollado siguiendo dos criterios de recogida de información: en primer lugar se ha realizado una exploración extensiva $y$, posteriormente, se ha acabado de definir la información a través de una exploración intensiva. El objetivo de la etapa de exploración extensiva ha sido recoger el mayor volumen de información sobre el número y distribución de niños procedentes de familias inmigrantes en los centros educativos de las comarcas del Camp de Tarragona, las experiencias comunicativas entre los centros y las familias, las demandas del profesorado y de las familias, los recursos con los que trabajan los centros, y la existencia de acontecimientos significativos escolares en relación con el alumnado inmigrante.

En un primer momento, en esta etapa de exploración extensiva se realizó un mapa educativo de la distribución de alumnado inmigrante en las escuelas públicas y privadas de estas comarcas. Esta tarea se realizó sobre fuentes secundarias obtenidas de las instituciones catalanas y, posteriormente, con datos contrastados a través de una encuesta telefónica a todos los centros educativos de las comarcas del Camp de Tarragona. En un segundo momento, se elaboró una muestra estructural de centros educativos que tenían estudiantes inmigrantes para realizar la recogida de información. Se utilizaron varios instrumentos de recogida de información: un 
RIS

REVISTA INTERNACIONAL DE SOCIOLOCIA

№ 36, Septiembre-Diciembre, 2003

IGNASI BRUNET, ANGEL BELZUNEGUI E INMA PASTOR

cuestionario dirigido a los directores y otro dirigido al profesorado de las escuelas, así como, también, entrevistas en profundidad a los directores de dichas escuelas para así comprobar de una manera más significativa los discursos sobre la integración social y educativa del alumnado de origen inmigrante. En concreto, se pasó el cuestionario a 577 profesores y se entrevistó a 118 directores de centros públicos y concertados.

En la etapa de exploración intensiva se llevaron a cabo entrevistas en profundidad a informadores privilegiados que trabajan en temas de inmigración y de inserción educativa, así como entrevistas a padres y madres de los niños escolarizados. También se organizaron grupos de discusión con profesores, por un lado, y con madres y padres por otro, para contrastar los discursos sobre los problemas relacionados con la integración educativa.

\section{ALGUNOS DATOS SOBRE INMIGRACIÓN}

La presencia de inmigrantes extracomunitarios residentes en España y en Cataluña es un fenómeno que representa una cierta novedad, teniendo en cuenta el lugar que ha ocupado tradicional e históricamente España como emisora de emigrantes en la búsqueda de mejores posibilidades económicas. Uno de los motivos de la inversión de la tendencia emisor/receptor es, en primer lugar, el crecimiento económico que, en general, se ha producido en todo el territorio y, en segundo lugar, la integración del país dentro de la Comunidad Europea. El crecimiento económico hace que el territorio sea más atractivo para los que vienen en busca de mejores condiciones económicas que no pueden encontrar en su país de origen; el segundo motivo hace atractiva la región como lugar de entrada en la UE, especialmente para los africanos, cuyo objetivo es establecerse en los países centrales y del norte de la UE.

Cataluña acoge una proporción ligeramente más elevada de inmigrantes extranjeros en comparación con el resto de comunidades. En 1990 Cataluña acogía al $16,2 \%$ de los extranjeros residentes en España. El año 2002 este porcentaje se situó en el 24,8\%. Otro indicador de importancia lo tenemos en la evolución de la población extranjera residente en Cataluña y España respecto de la población total. En la tabla 1 se presentan los porcentajes de población extranjera residente en relación con el total de población, para los dos ámbitos geográficos.

En Cataluña predominan los residentes extranjeros procedentes de África del Norte (33\%) (fundamentalmente población magrebí), seguidos de los procedentes de los países de la Unión Europea (26\%), y de los de América Central y Sur (20\%). Globalmente se pueden considar como inmigrantes económicos los procedentes de Europa del Este, América Central y del Sur, África del Norte, resto de África y Asia (excepto Israel y Japón): en cifras, más de un $69,74 \%$ de los residentes extranjeros en Cataluña se ajusta a este perfil. En el año 2002, el colectivo más 
Tabla 1.

\begin{tabular}{lcccc}
\hline \multicolumn{4}{c}{ Proporción de extranjeros respecto a la población total } \\
\hline & \multicolumn{2}{c}{ Extranjeros residentes } & $\begin{array}{c}\text { Porcentaje de extranjeros residentes } \\
\text { respecto a la población total }\end{array}$ \\
\cline { 2 - 5 } & 1990 & 2002 & 1990 & 2002 \\
\hline Cataluña & 65990 & 328461 & $1,10 \%$ & $5,10 \%$ \\
España & 407647 & 1324001 & $1 \%$ & $3,20 \%$ \\
\hline
\end{tabular}

Fuente: Elaboración propia a partir de datos del Instituto de Estadística de Cataluña.

importante numéricamente procede de África y, en particular, de Marruecos; los marroquíes representan el $31,42 \%$ del conjunto de la inmigración extranjera en Cataluña, y es la principal colonia extranjera en cada una de las cuatro provincias catalanas. La colonia marroquí (103.211) residente en Cataluña es la más antigua y numerosa de las ubicadas en España. Los asentamientos provisionales de la década de los 60 , fundamentalmente individuales, dieron paso a los grupos familiares a partir de los años 70. Posteriormente, a partir de la segunda mitad de los años 80 , se registró un mayor flujo y en constante incremento. El número de residentes subsaharianos en Cataluña va creciendo en los últimos años. Los dos colectivos más importantes proceden de Gambia (8.916) y Senegal (4.694). La gran mayoría son hombres solteros jóvenes de entre 20 y 35 años. Su llegada a Cataluña se inició hacia los años 70 , y se incrementó en los años 80 , años durante los que se instalaron básicamente en el Maresme y, desde allí, se fueron desplazando hacia otras zonas de Cataluña, básicamente, hacia las comarcas de Girona. Por otro lado, también en los últimos años cobra fuerza la presencia de latinoamericanos procedentes de Ecuador (20.209), Perú (15.125) y Colombia (10.920). El conjunto de inmigrantes latinoamericanos representan el $24,4 \%$ de los residentes extranjeros en Cataluña.

En esta comunidad autónoma, las comarcas que forman el Camp de Tarragona han experimentado esta última década un crecimiento económico importante en términos comparativos con el resto de comarcas catalanas. Este crecimiento ha posibilitado también un incremento de la población en las principales demarcaciones de estas comarcas, no tanto por el hecho de que se haya producido un incremento en las tasas de natalidad de los autóctonos, sino por el hecho de que se ha producido una concentración de población catalana (movilidad interna), así como de población extranjera alrededor, fundamentalmente, de las capitales de comarcas. Esta concentración de población ha tenido ciertas repercusiones sobre la escolarización de los hijos y ha creado problemas en los centros educativos como consecuencia de haber absorbido una demanda no esperada años atrás. 
RIS

REUISTA INTERNACIONAL DE SOCIOLOGIA

№ 36, Septiembre-Diciembre, 2003

IGNASI BRUNET, ANGEL BELZUNEGUI I INMA PASTOR

Respecto a la concentración de alumnos inmigrantes en algunas escuelas del Camp de Tarragona la situación es la siguiente:

1. Se observa un marcado proceso diferencial en la preinscripción y matriculación de alumnos inmigrantes entre escuelas, dependiendo de la zona geográfica, de tal forma que se crean concentraciones artificiales de alumnos extranjeros que superan con creces su peso en tanto por ciento en el territorio donde viven.

2. Una parte significativa de la población autóctona ha abandonado estas escuelas debido a su percepción de que la presencia de alumnos inmigrantes es motivo para cambiar la escolarización de sus hijos. El abandono de estos centros por parte de la población autóctona se ha producido en un momento de descenso demográfico, lo cual acentúa los procesos de concentración de inmigrantes.

3. Las escuelas concertadas han utilizado políticas de desvío del colectivo de inmigrantes para no verse absorbidas por la demanda y han acabado escolarizando parte de los hijos de la población autóctona que abandona los centros públicos.

Los centros que han experimentado un mayor crecimiento de alumnos inmigrantes en los últimos años se encuentran con el caso de que tienden a escolarizar principalmente alumnos procedentes de las familias con más bajas expectativas educativas. La distribución espacial de los centros educativos está vinculada a la composición socioeconómica y demográfica de los territorios (barrios, zonas residenciales, etc.). Los grupos sociales menos favorecidos económicamente optan normalmente por la opción de la escuela pública para la inserción educativa de sus hijos. Así es que una mayoría de las familias inmigrantes extracomunitarias, por sus características socioeconómicas, llevan a sus hijos a los centros públicos adscritos al territorio donde viven. Desde nuestro punto de vista, las familias autóctonas (las principales clientes de los centros privados y concertados) valoran varios aspectos a la hora de matricular a sus hijos en los centros no públicos: a) el hecho que los centros concertados puedan ofrecer la continuidad de los estudios desde los tres años hasta el final del bachillerato, mientras que los alumnos escolarizados en la red pública se ven obligados, en la mayoría de los casos, a cambiar de centro; b) por otra parte, la existencia de un ideario de centro con el que una parte de estas familias se identifica y que presenta una serie de valores compartidos que se quieren transmitir a su descendencia; c) la percepción social de que los centros concertados y privados dan una educación de mayor calidad al alumnado, en el sentido de mayor atención personalizada, mayor exigencia, etc., hecho que va en paralelo a la percepción de desprestigio de la escuela pública, y d) por último, también la percepción estos últimos años de que la escuela pública ha ido incorporando alumnado inmigrante, hecho que genera incertidumbre sobre el futuro educativo de los niños.

Como ya hemos apuntado, las familias inmigrantes y, sobre todo, las de origen extracomunitario, llevan a sus hijos mayoritariamente a los centros públicos de educación infantil y primaria. Las razones también son diversas: a) los costes educativos monetarios que han de soportar las familias si realizan la opción de 
la escuela pública o privada, aunque sea concertada; b) el desconocimiento del sistema educativo y la obligatoriedad de llevar a los niños a la escuela y, concretamente, al centro escolar asignado al lugar de residencia; c) la movilidad residencial y laboral que soportan una parte de las familias de inmigrantes, que hace que los niños puedan ser escolarizados en diversos centros a lo largo de su inserción educativa, dependiendo de los nuevos lugares de residencia de la familia; d) el rechazo por parte de algunas familias inmigrantes de los centros concertados confesionales por motivos religiosos; e) las estrategias que utilizan los centros privados concertados para evitar acoger a niños inmigrantes, para evitar la huida de una parte de las familias autóctonas.

También se debe tener en cuenta que en el proceso de concentración de niños inmigrantes en las escuelas públicas hay factores de otro orden que favorecen esta concentración, como, por ejemplo, los tipos de políticas migratorias orientadas a construir espacios de multiculturalismo jerarquizado y que optan por un modelo de escuela pública asistencial sólo para determinadas zonas y barrios. Estas políticas conducen a reforzar la etnificación de los individuos añadiendo al factor estructurador del mercado de trabajo la obligada localización geográfica como consecuencia de una política selectiva y de mercado de vivienda y de ocupación del espacio social urbano. Las posibilidades de acceso al trabajo y a la vivienda también influyen decisivamente en la creación de zonas urbanas donde se activan los procesos de etnificación.

A pesar de ello, desde nuestro punto de vista no se puede hablar de centros educativos transformados en guetos, aunque sí se observa que la concentración de inmigrantes en ciertas escuelas públicas (principalmente, aquéllas situadas en zonas donde los inmigrantes residen y se concentran) puede en el futuro plantear problemas de guetización en centros escolares públicos que han tenido que hacerse cargo de una situación que ellos mismos no pueden controlar.

La concentración de alumnos inmigrantes en las escuelas pone de manifiesto una falta de recursos para hacerle frente, debido a las demandas que el nuevo alumnado genera a lo largo de su proceso educativo. Algunos estudios (Aja, 2000; Siguan, 1998 e IOE, 1996) han puesto de manifiesto que en la educación primaria no se detectan numerosos problemas de convivencia del tipo choque de culturas, etc., sino que más bien se trata de un problema de sobrecarga de los recursos con los que cuentan las escuelas hoy en día. En relación con el tema de recursos se deben tener en cuenta dos factores: por un lado, que este volumen de recursos destinados a la comunidad educativa es escaso y determinado y, por otro lado, que la población que demanda y requiere estos recursos va creciendo en la medida que la mayor parte de la población inmigrante corresponde a los grupos sociales más bajos, es decir, más consumidores de las ayudas públicas. En este contexto, la escuela está actuando como elemento central que articula demandas familiares y servicios públicos. De alguna manera parece que la escuela esté actuando como escuela-red. 
RIS

REYISTA INTERNACIONAL DE SOCIOLOCIA

№ 36, Septiembre-Diciembre, 2003

IGNASI BRUNET, ANGEL BELZUNEGUI E INMA PASTOR

Además de la concentración de alumnado inmigrante, se ha puesto también de manifiesto que uno de los problemas fundamentales con los que se enfrenta la escuela es el de la distancia cultural entre les familias autóctonas y las familias de origen extranjero. Así, a mayor distancia cultural entre estas familias, mayor probabilidad de encontrar problemas convivenciales en el seno de la escuela. Teniendo en cuenta que nuestra investigación se centra en la enseñanza infantil y primaria, consideramos poco probable que se diesen problemas de convivencia entre niños inmigrantes y autóctonos motivados por sus adscripciones culturales, $\mathrm{o}$, al menos, que se diesen problemas convivenciales muy diferentes a los que podrían existir, por ejemplo, como resultado de las diversas procedencias socio-económicas y culturales entre los niños de la propia población autóctona. Por tanto, nos pareció importante trasladar la centralidad del análisis desde la variable procedencia, al proceso de reciprocidad y de comunicación (es decir, de interacción) entre las familias autóctonas, inmigrantes y la comunidad educativa. En este sentido, consideramos que la reproducción estricta de normas rígidas de vida basadas en creencias religiosas, como base de la etnicidad, podría dificultar la integración social de los inmigrantes. Dificultaría la integración en la medida en que los adultos inmigrantes mantienen y reproducen distancias respecto a los autóctonos y pretenden que sus hijos también reproduzcan unas conductas que sólo pueden ser aceptadas desde los valores generados por una determinada concepción religiosa de las normas sociales.

\section{MOVIMIENTOS MIGRATORIOS E INTEGRACIÓN}

Es necesario analizar la inmigración en un ámbito mayor de reflexión sobre la justicia en torno al problema político de quién está incluido dentro de una comunidad política —Estado-nación-y quién está excluido (Walzer, 1987). Por tanto, un primer debate necesario es el centrado en cómo el contacto entre inmigrantes y autóctonos puede llegar a construir o a deconstruir los derechos y los valores asociados a la ciudadanía democrática de las sociedades abiertas. La inclusión puede aplicarse a todos los inmigrantes o puede depender de variables como su cualificación técnica, su origen nacional, su lengua, su cultura, su nivel económico, esto es, la inclusión puede ser universal o selectiva. En principio, en términos de justicia la inclusión selectiva puede representar un menor grado de justicia que la inclusión universal, puesto que legitima la selección sobre la base de criterios de mercado y de procedencia (nacional, étnica, lingüística...), pero también puede tener un sentido "probatorio" $y$, por tanto, finalmente acreedor de derechos de ciudadanía, como, por ejemplo, el derecho a voto.

A la cuestión de la inclusión le subyace otra: ¿cómo alcanzar una sociedad democrática inclusiva sin amenazar la identidad nacional, de un Estado-nación o de una nación sin Estado? (Azurmendi, 2001; Sartori, 2001). Estas cuestiones hay que 
plantearlas y resolverlas admitiendo que, históricamente, todo el territorio europeo no es más que una historia de inmigración, y como tal — la inmigración-es parte integrante de los procesos de estructuración social de la modernidad, lo que lleva a afirmar que la inmigración es un reto de la modernidad reflexiva en el proceso de "salvaguardar el sistema político de derechos y libertades, el sistema de no explotación salvaje, y asegurar una ciudadanía no adscrita a formas etnonacionalistas o basadas en la xenofobia y el racismo" (Azurmendi, 2002: 29).

La inmigración constituye un tema caracterizado como problema en el debate político y social y centrado en torno a la pluralidad cultural y a la gestión de la diversidad. Pero a la vista de nuestras sociedades complejas, podemos preguntarnos qué sociedad no es pluricultural, independientemente de los flujos migratorios que la impactan. La cuestión depende de cómo analizamos los flujos dentro del llamado espacio de los lugares que tienden a materializarse en flujos interconectados y sin linealidad histórica (Castells, 1997; Bauman, 2001), y en los que subyace un individualismo institucionalizado que legitima la nueva organización del trabajo, la cual acentúa la movilidad de los factores productivos y la deslocalización de la actividad productiva al utilizar diversos espacios territoriales. Y la cuestión no es el multiculturalismo, sino la estructura multidimensional de las identidades, pues, como indica Lamo de Espinosa (1995: 26), "ni siquiera el cristianismo durante la Edad Media consiguió el monopolio de las identidades simbólicas. En ese sentido, todos somos multiculturales, pues todos, salvo los nativos de alguna cultura primitiva aislada - hoy ya casi inexistentes-, somos resultado del entrecruzamiento en nuestras biografias de rasgos y elementos culturales variados: la cultura religiosa en la que nos criamos, la localidad donde nacimos, la profesión que ejercemos, las lenguas que hablamos; todo ello ha marcado con intensidad variable nuestro carácter y formado nuestra mentalidad. $Y$ el difícil equilibrio de esas identificaciones alternativas y/o complementarias debe ser reconstituido cotidianamente en función de los contextos de acción, de las situaciones, de los talantes, de los interlocutores".

Desde esta ciudadanía multidimensional, el problema emerge cuando se convierte la igual inclusividad en una desigual segmentación, en separaciones culturales y sociales desintegrantes, no integrantes como consecuencia de la inferiorización y la diferenciación.

Frente a la segmentación y a la balcanización de la ciudad pluralista (Sartori, 2001; Azurmendi, 2001), la pluralidad cultural sólo es posible cuando está libre de sesgos racistas y es consistente con los principios democráticos, ya que "la salud y la estabilidad de las democracias modernas no sólo depende de la justicia de sus instituciones básicas, sino también de las cualidades y actitudes de sus ciudadanos; es decir, de su sentimiento de identidad y de cómo consideran a otras formas de identidad nacional, regional, étnica o religiosa que potencialmente pueden competir con la suya; de su capacidad de tolerar y de trabajar con personas distintas de ellos; de su deseo de participar en el proceso político para promover el bien 
RIS

REVISTA INTERNACIONAL DE SOCIOLOGIA

№ 36, Septiembre-Diciembre, 2003

IGNASI BRUNET, ANGEL BELZUNEGUI I INMA PASTOR

público y de apoyar a las autoridades políticas responsables; de su voluntad de demostrar comedimiento y de asumir su responsabilidad personal en sus exigencias económicas, así como en las elecciones personales que afecten a su salud y al entorno; y de su sentido de justicia y de su compromiso con una distribución equitativa de los recursos. Sin ciudadanos que posean estas cualidades, la capacidad de progreso de las sociedades democráticas disminuye progresivamente" (Kymlicka, 1996: 241-242). De ahí que la recepción de inmigrantes y la defensa de su modo de vida depende "de que sean capaces de adquirir formas de lealtad hacia (el) Estado de Derecho, porque en éste existen formas de vida cultural (no sólo política) que favorecen la lealtad constitucional" (Azumendi, 2002: 24).

Lo que plantea el pluralismo cultural es, también, una cuestión normativa o, más claramente, política y no necesariamente esencialista o metafísica. Dicho de otro modo, el pluralismo cultural proporciona dos lecciones acerca de las condiciones de la democracia pluralista, de la gestión democrática de las sociedades. La primera, que la democracia pluralista exige empezar por reconocer el carácter heterogéneo de nuestras sociedades, es decir, el reconocimiento de autonomía y pluralismo (De Lucas, 2001). Y esto obliga, ante todo, a descubrir su diversidad interna, previa, pero soterrada, pues la gestión política de la diversidad cultural ha consistido en negar, en eliminar, esa diversidad, y ello en nombre de una cultura que, como toda cultura, se manifiesta principalmente por medio de distinciones, divisiones, segregaciones, discriminaciones entre cosas o acciones, y definidas como legítimas. Por ello hay que reconocer la importancia de la pertenencia de los individuos a su propia cultura societal, en virtud del papel que ésta desempeña a la hora de posibilitar elecciones individuales significativas y sustentar la propia identidad, pues, aunque los miembros de una sociedad nacional no compartan ya valores morales o estilos de vida tradicionales, siguen teniendo una profunda vinculación con su lengua y su cultura propias. Y es precisamente el hecho de que la identidad nacional ya no descansa en valores compartidos lo que proporciona un fundamento sólido a la autonomía y a la identidad individual. La pertenencia cultural nos proporciona un contexto de elección inteligible y nos asegura un sentimiento de identidad y pertenencia, "sentimiento al que podemos recurrir para afrontar cuestiones acerca de los valores y los proyectos personales. Por otro lado, que la identidad nacional no requiera valores compartidos explica también por qué las naciones son las unidades apropiadas para la teoría liberal; los grupos nacionales ofrecen un ámbito de libertad e igualdad, así como una fuente de reconocimiento y de confianza mutuas, que pueden acomodar los inevitables desacuerdos y disensos sobre las concepciones del bien en la sociedad moderna" (Kymlicka, 1996: 149-150).

La segunda lección es que la democracia pluralista exige una lógica garantista e inclusiva; una lógica que postule la noción de igualdad compleja, de soberanía compartida, de ciudadanía diferenciada que cumpla con la función identitaria sin eliminar la función de status, como título formal de soberanía y derechos. Funcio- 
nes dificultadas por las nuevas formas de acumulación flexible que, al priorizar el mercado, fomentan el fenómeno de exclusión, de dualización, la fractura social y política a causa del aumento imparable de la desigualdad "que afecta sobre todo a quienes sufren una privación de ciudadanía (que les convierte no en infrasujetos de derechos sino en no sujetos) por motivos básicamente económicos y que se proyecta en la titularidad y el ejercicio de los derechos, en particular los sociales" (De Lucas, 2001: 100). Cabe pensar, pues, que en estas nuevas formas de acumulación la exigencia de asimilación cultural entre en crisis, pues el paro estructural pone en cuestión la integración económica asociada a la ciudadanía y debilita el sentimiento de pertenencia a una nación de la que se sienten socialmente excluidos, lo que dificulta la aceptación de los principios democráticos de convivencia, y refuerza el cierre comunitario, la tendencia a agruparse con individuos que se creen con similares referentes étnicos y aislarse de la sociedad; algo totalmente contrario a la idea de una sociedad plural, y es que el poder comunitario destruye la pluralidad cultural puesto que éste es völkisch, es decir, extrae su fuerza y su legitimidad de su identificación a una cultura (Touraine, 1998).

\section{INTERACCIÓN ENTRE LOS AGENTES DE LA COMUNIDAD EDUCATIVA Y LAS INSTITUCIONES}

La mayoría de países que forman la UE han adoptado medidas encaminadas a mejorar y hacer más efectiva la inserción educativa de los hijos de las familias inmigrantes. Pero en el trasfondo de esta idea común se está produciendo todo un debate sobre dos modelos más o menos enfrentados: un modelo multicultural centrado en el mantenimiento y la potenciación de los rasgos idiosincráticos de lo que se denominan comunidades étnicas. Se entiende aquí que los individuos han de adscribirse al comportamiento esperado de características étnicas tipificadas buscando como resultado una tolerancia entre culturas que apenas se modifican. Por otro lado, un modelo intercultural o pluricultural que persigue la integración de los inmigrantes a través del mestizaje y, por consiguiente, entiende las culturas como formas dinámicas y sitúa a los individuos en el centro de la asignación de derechos y deberes, y no a las comunidades etnificadas.

Hay que tener en cuenta que la integración educativa de los niños inmigrantes y de las familias no es algo que esté exclusivamente en manos del colectivo de educadores. Hay otros factores que influyen también en dicha integración, como son, por ejemplo, el acceso a la vivienda, subvenciones para material escolar, una política activa de apoyo a las mujeres inmigrantes, la alfabetización de los padres y las madres, la implicación de estos en la marcha escolar de sus hijos, etc. A medida que se ha extendido el fenómeno de la inmigración y, más en concreto, el de la inserción educativa de los niños de familias inmigrantes, se ha podido constatar la existencia de relación entre los déficits que presentan estos niños (no 
sólo derivados del desconocimiento del idioma del país receptor) y la situación socioeconómica de sus familias, $\mathrm{y}$, muy especialmente, el nivel de instrucción de los padres y las madres y sus experiencias con el sistema educativo de procedencia.

En la investigación que hemos llevado a cabo, el $61,1 \%$ de los directores entrevistados creen necesaria una política (o políticas) de acción positiva dirigidas a aquellos colectivos con menos recursos, entre los que se encuentran mayoritariamente los inmigrantes extracomunitarios. Se pretende que el impacto de las políticas de acción positiva se concrete en una mayor integración formativa del colectivo de inmigrantes, no sólo de los hijos, sino también, de las propias familias, hecho que ayudaría a conseguir mayores niveles de éxito en la integración a través de la implicación de los progenitores. Otra cuestión, más allá de las acciones estrictamente dirigidas a la inserción educativa de los niños de familias inmigrantes, es la política más amplia de acción positiva en referencia ả la mejora de las condiciones de vida, y, en concreto, a la obtención de trabajo y vivienda para los inmigrantes. Estas actuaciones tienen una gran importancia para favorecer su plena incorporación a la sociedad, y actúan positivamente sobre las condiciones materiales y psicológicas con las que llegan los niños al sistema educativo.

Sin embargo, no existe una opinión unánime sobre la eficacia y conveniencia de las políticas de acción positiva destinadas a los inmigrantes, ya que un $38 \%$ de los directores se manifiestan contrarios a que desde las administraciones públicas se pongan en marcha políticas de acción positiva dirigidas al alumnado inmigrante, ya que, según nuestros interlocutores, esto puede introducir mecanismos diferenciales entre la población autóctona más desfavorecida y las propias familias de inmigrantes, más teniendo en cuenta que la escuela pública es o se presenta como igualitaria en todos los aspectos.

En la línea de reflexión alrededor de las implicaciones de la existencia de políticas de acción positiva, una parte de los docentes consideran que, como contrapartida, la población inmigrada debe aceptar y hacer suyos los valores de convivencia basados en el respeto a los derechos individuales (considerando de forma prioritaria la igualdad como objetivo fundamental) y, por tanto, critican la formación de comunidades cerradas según criterios como la etnia o la religión. En la medida que se pide la aceptación de los valores asociados al ejercicio de la ciudadanía, la postura que mantienen estos docentes reclama que todas las políticas de acción positiva que se articulen, sean sometidas a la aceptación de este pacto social implícito. Así, también consideran necesario que las instituciones públicas garanticen la existencia de mecanismos de control sobre aquellos individuos que, amparándose en diferencias culturales, ponen en entredicho el ejercicio práctico de los derechos de los individuos. Es el caso, por ejemplo, de algunas familias musulmanas que desescolarizan a las niñas cuando llegan a una cierta edad, aun sabiendo que la escolarización en España es obligatoria hasta los 16 años. Entienden los maestros que a esas niñas se les está impidiendo un derecho elemental como es el de la educación: las decisiones de las familias colisionan 
con este principio fundamental, por lo que la Administración debería actuar para garantizarlo.

El análisis realizado muestra que las escuelas con alumnado inmigrante están llevando a término tres niveles de intervención ${ }^{2}$ en relación a la población inmigrada.

En un primer nivel, las escuelas intervienen promoviendo que otras instituciones desarrollen actuaciones de varios tipos. Es una intervención no estrictamente educativa o en un ámbito no propiamente educativo, pero que ha sido promovida por una buena parte del colectivo de docentes ante los condicionantes que otros factores, que también afectan a los inmigrantes, tienen sobre la acción educativa. Son iniciativas en la dirección de implicar a diversas instituciones para tratar de facilitar la integración social de los inmigrantes. Por ejemplo, las escuelas han promovido, en algunos casos, los contactos entre las asociaciones de mujeres de los municipios y las mujeres magrebís para ampliar los horizontes de relaciones sociales de éstas. En esta línea van las propuestas de una parte importante del colectivo docente que considera que la integración del alumnado pasa por la integración de las familias inmigrantes, y esto quiere decir tanto la integración económica (disponer de los recursos mínimos necesarios para sobrevivir), como la social (compartir, con el resto de ciudadanos la vida cotidiana).

Algunas escuelas han tomado la iniciativa de pedir a las administraciones locales la intervención de los servicios sociales para promover la formación de las madres en aspectos previos a la educación como, por ejemplo, la higiene, la sanidad, la salud, los hábitos sociales, etc. El cuidado de estos aspectos, que no son estrictamente educativos, son necesarios para garantizar el desarrollo de la actividad docente. Son necesidades que los docentes constatan pero sobre las que no pueden actuar si no es con la ayuda de la Administración. En este sentido, y básicamente la intervención más directa que ha llevado a término la Administración, es la articulación de la figura de los mediadores - figura, por otra parte, no exenta de controversia. Estos mediadores reconocen la necesidad de la intervención y manifiestan que, realmente, la llegada de población inmigrante, especialmente aquélla proveniente de zonas rurales muy poco desarrolladas y pertenecientes a grupos sociales muy desfavorecidos, genera un volumen de tarea extra para los centros escolares. En cualquier caso, la relación entre las familias y la escuela se considera fundamental para la buena integración de los hijos, pero también de los propios padres y madres. Esa idea es mayoritaria entre los entrevistados. Para los docentes, frente al proceso de etnificación, la escuela se manifiesta como un ámbito abierto de relación social entre personas de diversa procedencia. De hecho, la escuela puede ser el escenario en el que comience a materializarse esta

\footnotetext{
${ }^{2}$ Evidentemente, en función del volumen de población inmigrante vinculada al centro escolar, las actuaciones escolares son más o menos numerosas.
} 
RIS

REVISTA INTERNACIONAL DE SOCIOLOCIA

№ 36, Septiembre-Diciembre, 2003

IGNASI BRUNET, ANGEL BELZUNEGUI E INMA PASTOR

interrelación entre familias inmigrantes y familias autóctonas; se trata de crear espacios donde haya un mayor volumen de densidad de contactos, única forma en que puede llevarse a cabo una integración sobre valores compartidos. En concreto, algunas escuelas proponen, también, facilitar la integración a partir del trabajo con los padres y las madres, de forma que vayan incorporándose a reuniones de las asociaciones de madres y padres (AMPA) para hablar y comentar las actividades educativas del centro.

Hay una buena parte de los docentes que considera que los mecanismos existentes para integrar al alumnado en las escuelas son correctos ya que, en su opinión, no se hacen distinciones entre alumnado autóctono e inmigrante. Sin embargo, la percepción de los docentes es que una parte de las familias magrebíes mantienen un modo de vida muy cerrado en su propia comunidad y eso, consideran los entrevistados, dificulta la integración de los alumnos. Dificulta la integración en la medida que los adultos inmigrantes mantienen y reproducen distancias respecto a los autóctonos y pretenden que sus hijos también reproduzcan algunas conductas que sólo pueden ser aceptadas desde los valores generados por una determinada concepción religiosa de las normas ${ }^{3}$, la cual entra en contradicción con determinados derechos individuales como, por ejemplo, la actitud contraria a que las niñas cursen un curriculum exactamente igual al de los niños.

La inserción educativa está directamente relacionada con la inserción socioeconómica y, aunque ésta sea condición necesaria, no lo es al mismo tiempo suficiente, ya que para que realmente haya una inserción educativa con éxito, es necesario que la población inmigrada y la población autóctona compartan los mismos espacios públicos. Compartir la vida cotidiana pasa por no generar comunidades cerradas que mantengan relaciones exclusivamente con aquellos de su propia comunidad y que se definan por criterios étnicos o religiosos. Los mecanismos integradores pasan por poner en un plan de igualdad no a las comunidades concebidas como

\footnotetext{
${ }^{3} \mathrm{~A}$ título anecdótico relatamos el caso de unos niños cuyo padre no quería que comiesen cerdo $y$, por respeto, el comedor de la escuela preparaba, para estos niños, calamares en lugar de cerdo. A los niños no les gustaba los calamares y querían comer cerdo. El conflicto se daba, para el educador responsable del comedor, entre respetar la voluntad del padre o la del hijo. Los educadores dieron prioridad a la voluntad del padre sobre la de los hijos. A pesar del carácter anecdótico del caso, nos parece interesante destacar que, ante los procesos de integración, los conflictos denominados culturales muchas veces se trasladan al interior de las familias. $Y$ es que estos conflictos no son sino el fruto del choque entre la voluntad de cumplir o no, unos determinados deberes religiosos voluntariamente adquiridos. Los niños se educan en un contexto de laicidad creciente donde la obligatoriedad de ciertas normas religiosas pierde fuerza. Un caso paralelo es el de las chicas que no quieren llevar el pañuelo pero que lo hacen obligadas por los padres. Los maestros explican que habitualmente las niñas llevan el pañuelo obligadas por la familia. Esta grieta entre la voluntad de los padres y la voluntad de los hijos e hijas toma más protagonismo cuando se pasa a la educación secundaria.
} 
un colectivo homogéneo, las cuales pueden $-\mathrm{y}$ de hecho lo hacen - generar y reproducir mecanismos desigualitarios en su interior, sino poner en plano de igualdad a todos los individuos independientemente de su etnia, religión y sexo. Para Bassam Tibi (2003), la solicitud de des-etnización de la identidad de la sociedad receptora puede aplicarse también a la identidad de los inmigrantes ya que, de otro modo, el cambio y la tolerancia irían en una sóla dirección.

En definitiva, estos docentes están reclamando un pacto social en el que se acuerden los derechos y deberes de los inmigrantes y en el que haya un intercambio entre familias inmigrantes y Estado de acogida: ayudas económicas y servicios sociales públicos pero, por parte de los inmigrantes, aceptación de las normas autóctonas. Normas que, en opinión de la mayoría de los docentes entrevistados, si defienden es porque representan también beneficios para los inmigrantes como individuos. En el caso de las escuelas se está reclamando que los padres y madres inmigrantes acepten cuestiones como la asistencia y participación de forma igualitaria de los niños y niñas en todas las actividades curriculares (teatro, música, excursiones...). El análisis de este primer nivel de acciones que llevan a cabo las diferentes escuelas pone de manifiesto que la escuela está haciendo suya una función no explicitada previamente, que es la de actuar como intermediaria de otras instituciones y la de generar actuaciones específicas a partir de la detección de necesidades en determinados colectivos. Los docentes reclaman más participación de la Administración y, sobre todo, más coordinación entre los diferentes actores implicados en los servicios sociales y educativos.

En un segundo nivel las escuelas han promovido acciones nuevas desde la propia escuela. De la información recogida destaca el hecho de que, en general, y de forma casi unánime, los docentes acogen a los inmigrantes con alegría y entusiasmo y este sentimiento es trasladado al aula y, por tanto, al resto de alumnado. Los docentes celebran la llegada e incorporación de un alumno inmigrante y procuran generar alrededor de este hecho un clima de acogida y fiesta. Además, habitualmente, la llegada de un nuevo alumno es utilizada como excusa para trabajar determinados conocimientos o unidades temáticas en las diferentes asignaturas, como, por ejemplo, el conocimiento de un país nuevo - el de origen del inmigrante- en ciencias sociales, palabras nuevas en el área de lengua, costumbres de otros países en ciencias sociales, etc.

$\mathrm{Y}$ es que con motivo de la incorporación de alumnado inmigrante se han puesto en marcha, por una parte, acciones nuevas propiamente educativas. Son fundamentalmente acciones que buscan facilitar la adquisición de conocimientos por parte del alumnado inmigrante procurando el máximo éxito escolar: grupos de refuerzo, clases de repaso...También, en una buena parte de los centros en que se ha constatado en estos últimos años la incorporación de población inmigrante, se ha generado la necesidad de revisar y reformar el Proyecto Educativo de Centro (PEC) para reflejar la diversidad existente en el mismo.

En un tercer nivel, encontramos iniciativas personales de algunos maestros. 
Fundamentalmente son iniciativas dirigidas a promover el aprendizaje y la adquisición de conocimientos por parte del alumnado: muchos de los docentes elaboran su propio material didáctico a la hora de trabajar con este alumnado. También hay que destacar que la implicación de muchos docentes va más allá de la actividad académica intentando cubrir otros intereses y necesidades formativas del alumnado. Los maestros promueven un trabajo con las familias con el objetivo de que éstas permitan a los hijos o hijas (habitualmente los problemas se presentan más con éstas) hacer aquellas actividades previstas por el maestro o maestra.

Para identificar el origen de las actitudes de los inmigrantes, más contrapuestas a las prácticas habituales en las sociedades de acogida, muchas veces se hace referencia, por parte de muchos docentes, y también como opinión presente en una buena parte de la población, a la diferencia de culturas. En algunos casos, se explica esta actitud como el resultado del bajo nivel educativo de algunas de las familias inmigrantes, y sin duda que esto es así en el caso de familias de origen rural que han tenido poco o ningún contacto con el sistema educativo en su país de origen. Sin embargo, lo que habitualmente más se utiliza para explicar unas actitudes, unos valores o unos comportamientos que no comprendemos o no aceptamos es la referencia a orígenes culturales diversos o a distancias culturales entre la población inmigrante y la población autóctona. Pero ésta es una utilización de la palabra cultura que refleja una postura acrítica con los contenidos, las prácticas y los comportamientos que se llevan a cabo y quedan justificados en aras de una posición relativista.

De hecho, tal y como apunta Goytisolo" "El respeto a la libertad de credos y hasta razones de simple cortesia suelen ser la causa de que habitualmente reciba la consideración de rasgo cultural lo que de hecho no es más que el cumplimiento de un precepto religioso. Por supuesto que todas las religiones acostumbran a informar los hábitos culturales de sus seguidores, por lo que no siempre resulta fácil separar una cosa de la otra, pero lo cierto es que cuando se habla de choque de culturas, los aspectos más conflictivos son indefectiblemente los que se hallan regidos por un imperativo religioso".

Sin embargo, el hecho de que estas actitudes y comportamientos contrapuestos al modo de vida occidental se den en relación a algunos de los inmigrantes de origen magrebí pero no a todos, pone de manifiesto que aquello que realmente se está evidenciando no es un hecho característico fruto de un origen étnico determinado, sino concepciones diversas existentes en las familias y en los individuos a la hora de valorar la educación y otros derechos. $Y$ es que, a veces, el término cultura se utiliza como una palabra comodín. Tal y como dijo uno de los mediadores entrevistados: "Porque no encuentran una respuesta a un problema... 'ah, ese es de otra cultura'. Esta es la respuesta a sus problemas. Y esto es lo malo y lo raro, porque eso quita el peso o

${ }^{4}$ El País, 2/11/2002. 
quita el interés por actuar con esa persona o de solucionar el problema, porque es cultura y entonces ya lo tiene todo...".

Este uso acrítico del concepto cultura no está presente sólo entre los autóctonos sino también entre los inmigrantes. Entre estos también hay referencias a especificidades culturales a la hora de justificar algunos de sus comportamientos que chocan con los valores occidentales basados en el respeto a los derechos individuales. Un ejemplo puede ser la justificación de la discriminación por razón de sexo por parte de algunas familias en base a principios y creencias religiosas. No es este un tema baladí ya que en las entrevistas realizadas se ha puesto de manifiesto que algunos padres magrebíes han reclamado la educación diferenciada por sexos argumentando la superioridad masculina ante las mujeres. Igualmente se justifica la no participación de las mujeres/madres en la vida social - éste es un punto más evidente en las zonas rurales que en las urbanas-, la no-participación de las hijas en algunas actividades, la obligación de llevar una determinada indumentaria por parte de las hijas, la obligación de las mujeres de someterse a los hombres y la justificación de la no-aceptación, por parte de los varones, de la autoridad de las maestras mujeres. Comportamientos todos estos que, de manera reiterada y acompañados de evidente preocupación por parte de los docentes se han puesto de manifiesto a lo largo de las entrevistas realizadas. $Y$ es que, en la información recogida, la frase "Tú no me mandas porque eres mujer", dicha por alumnos varones magrebíes es más habitual de lo que sería deseable. El problema es que esta actitud es fomentada y reproducida desde las familias. En este punto, la defensa del valor de la coeducación y la igualdad entre sexos se manifiesta como un tema prioritario e irrenunciable ${ }^{5}$. Y el desencuentro y la confusión continúan y se retroalimentan cuando se afirma que del respeto que se ha de tener a cualquier creencia religiosa, se deduce el respeto a cualquier cultura, una vez que ésta se traslada fuera del marco social del que surgió. Así, dando la voz otra vez a Goytisolo cabe afirmar que "los rasgos culturales — respondan o no a un mandato religioso - son no sólo enjuiciables, esto es, susceptibles de ser evaluados por la razón, sino también adecuables en grado muy diverso a la evolución general de las costumbres".

\footnotetext{
${ }^{5}$ En esta línea se posiciona uno de los mediadores entrevistados cuando reclama que la Administración intervenga directamente sobre todos aquellos individuos que, en nombre de tradiciones, religiones o culturas, llevan a la práctica comportamientos que interfieren en el respeto a los derechos individuales. Para hacer respetar los derechos individuales muchos de los entrevistados piden el control sobre estas actuaciones de manera que, por ejemplo, el poder disfrutar de ayudas económicas o de cualquier otro tipo quede condicionado al cumplimiento de las normas básicas vigentes en la sociedad de acogida.
} 


\section{CONCLUSIONES}

Siguiendo la línea expositiva previamente apuntada, la mayoría de los entrevistados consideran que la integración educativa del alumnado inmigrante en educación infantil y primaria no plantea ningún problema cuya base esté en las diferencias de procedencia del alumnado y que, de hecho, la intervención educativa hacia los inmigrantes se hace en función de detectar las necesidades de los niños y esto se hace así para cualquier alumno. Es decir, los docentes resaltan que la función de la escuela es acoger al alumnado y transmitir unos conocimientos y esto se hace con todo el mundo, independientemente de su lugar de origen. En función de las características del niño el proceso de acogida se hará potenciando unas dimensiones u otras para garantizar el éxito de la inserción educativa, pero en igualdad de condiciones para el alumnado.

Sea como sea, el profesorado entrevistado considera, en general, que las escuelas ya están poniendo en marcha las medidas que consideran necesarias y que pueden aplicar: trabajo con las familias mediante el mediador para explicar el funcionamiento de la escuela, apoyo económico para garantizar las necesidades educativas de los niños, apoyo lingüístico a familias y niños para facilitar la comunicación, reuniones con servicios sociales para analizar el caso de familias, mentalización de los docentes en relación con la problemática de los recién llegados. A partir de esta tarea, la responsabilidad queda en manos de las propias familias inmigrantes de las cuales se espera implicación y compromiso con las necesidades educativas de los hijos. Es decir, la mayoría de los docentes considera que la escuela juega un papel limitado y que son otras las instancias que también deberían implicarse, ya que hay otros elementos que interfieren en esta relación y que, según cómo se planteen, pueden ser facilitadores o dificultadores del proceso educativo de los niños. Pero en esta línea, la intervención que se reclama ya no tiene por objetivo el alumnado sino sus familias; respecto a éstas sí que se pueden, dice el profesorado entrevistado, plantear determinadas actuaciones sociales.

Tal y como se pone de manifiesto en nuestro estudio, el origen de los conflictos identificados se encuentra en la aplicación o exteriorización de determinadas creencias religiosas en el seno de lo que hemos denominado proceso de etnificación de las comunidades de inmigrantes. Esta conclusión se ve apoyada por estudios como los realizados por Bassam Tibi (2003: 78), quien afirma que "las identidades étnicas son identidades excluyentes que, cuando se cultivan en la diáspora, originan una especie de neoabsolutismo con sus correspondientes conflictos sociales". No podemos pasar por alto el hecho de que, según las informaciones recogidas, los conflictos que se manifiestan en algunas escuelas son fruto, fundamentalmente, de los efectos de la aplicación rigurosa por parte de algunas familias islámicas de sus creencias religiosas, creencias que chocan con los valores de tipo universalista que nuestra sociedad encarga a la escuela que transmita. Cabe insistir en que las escuelas están jugando un importante papel en 
la medida en que actúan cómo mecanismos impulsores y garantes de los valores que fundamentan las sociedades occidentales, el laicismo y la democracia. En este sentido se deben entender las reclamaciones que se hacen desde los centros escolares en demanda de más apoyo por parte de la Administración.

\section{REFERENCIAS BIBLIOGRÁFICAS}

AJA, E. (2000), Educació i immigració: els reptes educatius de la diversitat cultural i l'exclusió social, Barcelona, Barcelona Mediterrània.

AZURMENDI, M. (2001), Estampas de El Ejido, Madrid, Taurus.

(2002), "Inmigración e identidad ciudadana”, Claves de Razón Práctica, nº 128, pp. 21-30, Madrid.

BAUMANN, Z. (2001), La sociedad individualizada, Madrid, Cátedra.

CASTELLS, M. (1997), "La era de la información. Economía, sociedad y cultura", La sociedad red, Vol. 1, Madrid, Alianza Editorial.

COLECTIVO IOE (1996), La educación intercultural a prueba, Granada, Proyecto Sur Ediciones.

DE LUCAS, J. (2001), “Ciudadanía y Unión Europea intercultural”, Revista Anthropos Huellas del conocimiento, $\mathrm{n}^{\circ}$ 191, pp. 93-116.

KYMLICKA, W. (1996), Ciudadania multicultural, Barcelona, Paidós.

LAMO DE ESPINOSA. E. (1995), "Fronteras culturales" en Lamo de Espinosa, E. (ed.), Culturas, Estados, ciudadanos, Madrid, Alianza Editorial.

SARTORI, G. (2001), La sociedad multiétnica. Pluralismo, multiculturalismo y extranjeros, Madrid, Taurus.

SENNET, R. (2001), "La calle y la oficina: dos fuentes de identidad", en Giddens, A. y Httonn, W. (eds.), En el limite. La vida en el capitalismo global, Barcelona, Tusquets.

SIGUAN, M. (1998), La escuela y los inmigrantes, Barcelona, Paidós.

TIBI, B. (2003), “Los inmigrantes musulmanes de Europa, entre el Euro-Islam y el gueto", en Nezar Alsayyad y Manuel Castells (eds.), ¿Europa musulmana o Euro-Islam? Política, Cultura y Ciudadanía en la era de la globalización, Madrid, Alianza.

TOURAINE, A. (1998), Igualdad y diversidad, México, Fondo Cultura Económica.

WALZER, M. (1987), Spheres of Justice, Nueva York, Basic Books.

WIHTOL DE WENDEN, C. (2000), ¿Hay que abrir las fronteras?, Barcelona, Edicions Bellaterra.

ZAPATA, R. (2001), "Ciudadanía e interculturalidad: razones para un balance”, Revista Anthropos, $n^{\circ} 191$, pp. 21-40, Barcelona. 